\title{
Política de valorização do magistério público: os planos de cargos, carreira e remuneração das redes estadual do Rio Grande do Norte e municipal de Natal e o piso salarial profissional nacional
}

\author{
Magna França ${ }^{1}$ \\ magna@ufrnet.br
}

Fádyla Késsia R. de Araújo ${ }^{2}$

fadyla_kessia@hotmail.com

Janaina Lopes Barbosa ${ }^{3}$

Janaina_lopes3009@yahoo.com.br

Maria Aparecida dos S. Ferreira ${ }^{4}$

cidasantosf@bol.com.br

Mônica Moreira dos Santos 5

monicamoreira13@yahoo.com.br

Rosângela Maria de O. Silva ${ }^{6}$

rosadomingos@yahoo.com.br

\footnotetext{
1 Doutora em Educação pela Universidade Federal do Rio Grande do Norte (2001). Professora da Universidade Federal do Rio Grande do Norte.

2 Mestranda em Educação pela Universidade Federal do Rio Grande do Norte.

3 Pedagoga pela Universidade Federal do Rio Grande do Norte (2011). Bolsista de Iniciação Científica. 4 Bolsista do Projeto de Pesquisa "Remuneração salarial dos professores da educação básica", do Observatório da Educação - CAPES/MEC. Doutoranda - PPGEd/CE/UFRN.

5 Estudante de Pedagogia da Universidade Federal do Rio Grande do Norte.

6 Doutoranda em Educação pela Universidade Federal do Rio Grande do Norte.
} 


\section{Resumo}

Este estudo analisa os Planos de Cargos, Carreira e Remuneração da rede estadual do Rio Grande do Norte e da rede municipal de Natal, especificamente sobre a remuneração salarial e o impacto do Piso Salarial Profissional Nacional de 2008. Teoricamente, tem respaldo em documentos e legislações que norteiam a política de valorização do magistério relacionados com a remuneração dos professores da educação básica, a saber: Emendas Constitucionais n. 14/96 e n. 53/06, relacionadas ao Fundef e ao Fundeb, respectivamente; Lei do Piso Salarial Profissional Nacional n. 11.738/08; Lei n. 322/06, que normatiza o Plano de Cargos, Carreira e Remuneração estadual do Rio Grande do Norte; Lei n. 58/04, relativa ao Plano municipal de Natal e a Resolução do Conselho Nacional de Educação n. 02/09 que normatiza as diretrizes para a carreira do magistério. Além desses estudos, elaboraram-se instrumentos que permitiram visualizar as remunerações implementadas com os Planos, cujos valores demonstram o período que antecede e o a posteriori, com a implementação do Piso Nacional 2008. Hoje, o Fundeb é a principal fonte de recursos para a valorização da carreira do magistério, pois aporta recursos de, no mínimo, $60 \%$ de sua arrecadação para a manutenção dos Planos de Cargos, Carreira e Remuneração. Reconhecemos que muitos avanços têm permeado a carreira do magistério estadual no Rio Grande do Norte, ocorrendo ganhos com a implementação do Piso. Porém, na carreira docente municipal de Natal, esta não apresentou melhorias salariais, constatando, porém, que esse município vem aplicando, em média, 95\% dos seus recursos na remuneração dos profissionais da educação.

Palavras-chave: Fundeb; Planos de Carreira; Piso Salarial Nacional.

\section{Introdução}

Para a educação básica, a política de Fundos (Fundef e Fundeb) passa a ser a principal diretriz, na medida em que visa a implementar ações legais e diretrizes técnicas voltadas para a valorização do magistério 
público brasileiro e, em especial, para a remuneração, em face dos Planos de Cargos, Carreira e Remuneração (PCCR) e do Piso Salarial Profissional Nacional (PSPN).

O Fundo de Manutenção e Desenvolvimento da Educação Básica e de Valorização dos Profissionais da Educação (Fundeb) se caracteriza como um fundo de natureza contábil sendo, pois, uma das maiores fontes de recursos para financiar a educação e a valorização de todos os profissionais da educação básica. Parte dos recursos arrecadados deve ser aplicada em planos de cargos e carreiras dos estados e municípios, em um quadro legal definitivo, conforme determina o artigo n. 206 da Constituição Federal de 1988 (BRASIL, 1988).

É evidente que a Lei do PSPN n. 11.738/08, proveniente da Lei n. 11.494/07, que regulamentou o Fundeb, vem imprimir novo patamar legal e financeiro para enfrentar a questão da valorização do magistério, em atendimento à Emenda Constitucional n. 053/06.

No desenvolvimento deste texto, procurou-se delinear uma análise sucinta relativa aos referenciais teóricos e à legislação sobre a valorização do magistério dando ênfase à remuneração salarial, trazendo como destaque os planos de cargos e carreiras do magistério público municipal de Natal e estadual do Rio Grande do Norte e o PSPN. Desenvolveu-se uma análise sobre as respectivas remunerações salariais configurando os valores e as categorias dos Planos a um espaço que antecede e outro que é a posteriori à implementação do PSPN no período de 2006 a 2010.

Ressalta-se, entretanto, que este estudo decorre de parte de uma pesquisa nacional, abrangendo outros indicadores educacionais, sobre a "remuneração salarial dos docentes" desenvolvida por instituições de educação superior públicas, organizadas em um sistema de rede coordenado pela Universidade de São Paulo, e vinculada Observatório da Educação, projeto de fomento ao desenvolvimento de estudos e pesquisas em educação, sob a gestão conjunta da Fundação Coordenação de Aperfeiçoamento de Pessoal de Nível Superior (CAPES) e do Instituto Nacional de Estudos e Pesquisas Educacionais Anísio Teixeira (INEP). 


\section{Valorização do magistério público: diretrizes e legislação}

A política de valorização do magistério docente no contexto do financiamento da educação básica, a partir da década de 1990, nos remete a uma reflexão breve sobre os seus aspectos legais, dentre eles: a Constituição Federal de 1988; a Lei n. 9.394/96, que contém as Diretrizes e Bases da Educação Nacional (LDB); a Emenda Constitucional n. 14/96, que instituiu o Fundo de Manutenção e Desenvolvimento do Ensino Fundamental e de Valorização do Magistério (Fundef); a Lei n. 9.424/96, que regulamentou o Fundef; a Emenda Constitucional n. 53/06, que instituiu o Fundeb; a Lei n. 11.494/07, que regulamentou o Fundeb; a Lei n. 11.738/2008, que dispôs sobre o PSPN; e, ainda, a Resolução do Conselho Nacional de Educação n. 02/09, que normatizou as diretrizes para a carreira do magistério.

A Constituição Federal de 1988, após um amplo debate sobre o financiamento da educação, teve alguns dos seus artigos aprovados em defesa dos recursos destinados à educação pública, imprimindo um percentual de aplicação na manutenção do ensino básico na ordem de $18 \%$ pela União e de $25 \%$ para os estados e municípios. Com relação ao profissional docente, essa Constituição garantiu, ainda, planos de carreira para o magistério público, com piso salarial profissional e ingresso na carreira via concurso público (BRASIL, 1988).

Em decorrência dessa determinação legal e em face da necessidade de garantir recursos contábeis à manutenção do ensino fundamental e à valorização da carreira do magistério, a Emenda Constitucional n. 14/96 (BRASIL, 1996a) modificou os artigos 34, 208, 211 e 212 da citada Constituição e deu nova redação ao artigo 60 de suas Disposições Transitórias indicando uma nova forma de redistribuição dos recursos, originando, assim, a Lei n. 9.424/96 que instituiu o Fundef. Essa Lei estabeleceu, ainda, que uma proporção não inferior a $60 \%$ dos recursos de cada Fundo estadual seria destinada ao pagamento (complementação salarial) dos professores do ensino fundamental, bem como à formação desses docentes do magistério, em exercício (BRASIL, 1996b).

Com relação à valorização do magistério, a LDB, no seu artigo 68, 
determinou a origem dos recursos para o financiamento da educação, reforçou, nos artigos 67 e 70, que a remuneração dos profissionais da educação constitui despesa de manutenção e desenvolvimento do ensino e estabeleceu que os sistemas de ensino devem promover a valorização dos profissionais da educação assegurando-lhes, inclusive nos termos dos estatutos e dos planos de carreira do magistério público, (a) o ingresso por concursos públicos; (b) o aperfeiçoamento profissional; (c) o piso salarial profissional com progressão funcional, baseado na titulação ou habilitação e na avaliação de desempenho; (d) o período reservado aos estudos e planejamento e, ainda, (e) as condições adequadas de trabalho (BRASIL, 1996c).

Com a proposta de estabelecer as diretrizes nacionais, o Plano Nacional de Educação (PNE) 2001-2010, aprovado pela Lei n. 10.172/01, trouxe, em sua concepção, uma preocupação com a qualidade da educação e pressupôs a realização de alguns eixos importantes que norteariam os planos das unidades federadas: formação profissional permanente e continuada, melhorias das condições de trabalho docente e planos de cargos e carreiras para o magistério público (BRASIL, 2001).

A Emenda Constitucional n. 53/06, que instituiu o Fundeb, imprimiu nova redação aos artigos $7^{\circ}$, 23, 30, 206, 208, 211 e 212 da Constituição Federal de 1988, normatizando a cooperação entre a União e as entidades federativas na execução de programas de educação e valorização dos profissionais da educação escolar (BRASIL, 2006).

Com a Lei n. 11.494/07, que regulamentou o Fundeb, continuou central o debate sobre a valorização profissional dos educadores como o detalhamento das responsabilidades dos entes federativos com essa política. O seu artigo 40 especificou que os estados, os municípios e o Distrito Federal deveriam implantar planos de carreira e remuneração dos profissionais da educação básica de modo a assegurar as mesmas condições elencadas no PNE 2001-2010: remuneração condigna, integração entre o trabalho docente e a proposta pedagógica, capacitação profissional e melhoria da qualidade do ensino. A referida Lei, em cumprimento à Emenda Constitucional n. 53/06, também determinou, em seu artigo 22, que, pelo menos, $60 \%$ dos recursos anuais totais do 
Fundo seriam destinados à remuneração dos profissionais do magistério da educação básica (BRASIL, 2007).

\section{Piso Salarial Profissional Nacional - 2008}

A Lei do Piso veio regulamentar a carreira do magistério público em face do cumprimento dos dispositivos legais constantes na Constituição Federal de 1988, na Emenda Constitucional n. 53/06 e na Lei n. 11.494/07 que explicitou, no artigo 41, que o poder público deveria fixar o piso salarial nacional para os profissionais do magistério da educação básica por meio de lei específica. Assim, em 16 de julho de 2008, foi sancionada a Lei n. 11.738 dispondo sobre o Piso Salarial Profissional Nacional (BRASIL, 2008). O artigo $2^{\circ}$ da Lei fixou o valor de $R \$ 950,00$ como piso salarial para docentes com formação em nível médio com uma jornada de, no máximo, 40 horas semanais. No parágrafo $3^{\circ}$ desse artigo, esclareceu que os vencimentos iniciais referentes às demais jornadas de trabalho seriam proporcionais ao valor mencionado. Determinou também, no parágrafo $4^{\circ}$, que na composição da jornada de trabalho observar-se-ia o limite máximo de 2/3 da carga horária para o desempenho das atividades de interação com os educandos e 1/3 para a formação e preparação para a docência.

O Piso refere-se ao vencimento inicial mínimo de qualquer uma das carreiras do magistério da educação básica - atividades de docência ou suporte pedagógico. Os valores podem e devem ser mais elevados nas unidades federativas que tiverem condições de remunerar melhor a categoria.

Vale ressaltar que as organizações sindicais, científicas e acadêmicas docentes tiveram papel primordial nesse contexto de aprovação do Fundeb e da Lei do Piso, ocorrendo, inclusive, embates entre a Confederação Nacional dos Trabalhadores em Educação (CNTE), o poder executivo e o legislativo. A CNTE teve destaque dialogando com os trabalhadores em educação e conclamando a sociedade brasileira à luta, junto ao Congresso, no período de 2007 a 2009, visando à aprovação da respectiva Lei do Piso.

Em relação à Portaria Ministerial n. 211, de 10 de março de 2009, que 
estabeleceu o valor mínimo nacional por aluno do Fundeb (BRASIL, 2009a), a CNTE reforçou o elo entre o Fundeb e o PSPN do magistério esclarecendo que esse valor deveria ser ajustado em $19,2 \%$ cujo percentual passou a valer para reajustar o PSPN de 2009. Assim, o valor de R \$950,00, definido para 2008, deveria ser de $\mathrm{R} \$ 1.132,00$ e, daí por diante, conforme valor per capita do Fundeb definido pelo Ministério da Educação (MEC). Isso porque $60 \%$ do valor per capita do Fundo, previsto para a vigência anual, destina-se à remuneração dos profissionais do magistério. Por essa lógica, o Piso, em 2010, corresponderia a R\$1.312,85 e passaria a ser de $\mathrm{R} \$ 1.513,58$, em 2011, caso o percentual de reajuste se mantivesse em 15,29\%. Vale salientar que esses valores não correspondem àqueles aprovados pelo governo federal, conforme informações contidas na TAB. 1 a seguir:

\section{TABELA 1}

Proposição da CNTE e os reajustes com a Lei do PSPN na Remuneração base dos professores- Rio Grande do Norte

\begin{tabular}{l|c|c|c|c|c}
\hline \multicolumn{3}{c|}{ REAJUSTES DO PSPN } & \multicolumn{3}{c}{ REAJUSTES DO PSPN } \\
NA VISA n. 11.738/08 DO CNTE & \multicolumn{3}{c}{} \\
\hline Ano & Índice (\%) & Valor (R\$) & Ano & Índice (\%) & Valor (R\$) \\
2008 & - & 950,00 & 2008 & - & 950,00 \\
2009 & 19,2 & $1.132,40$ & 2009 & - & 950,00 \\
2010 & 15,93 & $1.312,85$ & 2010 & 7,86 & $1.024,67$ \\
2011 & 15,29 & $1.513,58$ & 2011 & 15,294 & $1.181,34$ \\
\hline
\end{tabular}

Fonte: CONFEDERAÇÃO NACIONAL DOS TRABALHADORES EM EDUCAÇÃO, 2010.

O atual valor mínimo do Fundeb, conforme Portaria Ministerial n. 538, para 2010, é de R 1.414,85 (BRASIL, 2010). Em se mantendo esse valor até a aprovação das Leis Orçamentárias, o PSPN deve acumular um reajuste de 15,29\%, que representa a diferença per capita do Fundo da Educação Básica entre 2009 e 2010 a ser considerada, em 2011, para o Piso Salarial do Magistério.

Mesmo com as limitações que, provisoriamente, o Supremo Tribunal Federal (STF) impôs ao alcance do Piso Salarial por força de uma 
Ação Direta de Inconstitucionalidade (ADI) ${ }^{7}$ impetrada por um grupo de governadores brasileiros, principalmente no que diz respeito à composição da jornada semanal, o que se tem garantido, com a Emenda Constitucional n. 053/06, do Fundeb, é mais recursos de impostos para a aplicação em planos de carreira dos estados e municípios.

Ocorre, porém, que alguns estados e muitos municípios ainda questionam esses valores considerando a liminar do STF. Outros, alegam não ter disponibilidade de recursos para implementar os respectivos Planos de Carreira e Remuneração. Como exemplo, os baixos salários de vários estados das regiões Norte e Nordeste, com exceção dos estados de Alagoas e Tocantins. Entretanto, outros estados considerados ricos, como Minas Gerais e Santa Catarina, não alcançam o previsto pelo Piso Salarial (BRASIL, 2009b).

É evidente que no magistério, por ser uma profissão que envolve um contingente significativo de trabalhadores, o limite da remuneração dos professores é dado essencialmente pela dimensão da receita tributária arrecadada pelo estado e pela disputa entre os diferentes segmentos que a demandam.

\section{Rede pública estadual do Rio Grande do Norte: o PCCR e o PSPN no período 2006-2010}

A Lei Complementar n. 322/06, do Poder Legislativo do estado do Rio Grande do Norte, dispôs sobre o Estatuto e o Plano de Cargos, Carreira e Remuneração do Magistério Público Estadual referente à Educação Básica e à Educação Profissional. No inciso I do artigo $2^{\circ}$, definiu o conceito de Magistério Público Estadual como sendo “o conjunto de servidores públicos efetivos, legalmente investidos no cargo público de Professor e no cargo público de Especialista de Educação, que exercem funções de magistério nas Unidades Escolares [...]" (RIO GRANDE

\footnotetext{
7 O Supremo Tribunal Federal vetou o $\S 4^{\circ}$ do artigo $2^{\circ}$ da Lei do Piso Salarial Nacional que trata da carga horária. O parágrafo estabelecia o limite máximo de $2 / 3$ (dois terços) para o desempenho em sala de aula e 1/3 para extraclasse. Com a decisão do STF, são os Municípios e Estados que definem a distribuição da carga horária. Esclarece que os termos 'vencimentos iniciais' e 'salário inicial', ficam entendidos como 'remuneração total inicial'. Ou seja, transformou-se o Piso Salarial em Teto Salarial. Após um período de embates, o Tribunal considerou o que propõe a Lei do Piso.
} 
DO NORTE, 2006). Definiu, também, nos incisos II, III, IV, V, VI e VII do artigo $2^{\circ}$, conceitos referentes às funções do magistério, funções de suporte pedagógico, funções de docência, hora-docência, hora-atividade, jornada de trabalho e cargo público (RIO GRANDE DO NORTE, 2006).

O PCCR/RN definiu os princípios básicos do Magistério Público Estadual, nos incisos de III a VI do artigo $4^{\circ}$, e garantiu a valorização do magistério nos seguintes aspectos: remuneração digna; profissionalização - que pressupõe vocação e dedicação ao magistério, habilitação profissional e condições adequadas de trabalho; aperfeiçoamento profissional e atualização dos conhecimentos; evolução funcional baseada na avaliação do desempenho e na aquisição de titulação. Quanto à avaliação de desempenho, o PCCR/RN definiu que a mesma deverá observar os seguintes critérios: desempenho da função, produção intelectual, qualificação e rendimento dos alunos (RIO GRANDE DO NORTE, 2006). Entretanto, essa política ainda não se efetivou tendo em vista que, até então, não foi formada a Comissão de Avaliação.

Tomando como referência os princípios citados, O PCCR/RN definiu a estrutura da carreira dos profissionais estatutários com cargos de provimento efetivo de professores e especialistas de educação. Desse modo, a carreira do professor permanente está organizada em seis Níveis ${ }^{8}$ e dez Classes, ${ }^{9}$ e a de Especialista de Educação em cinco Níveis e dez Classes. No caso da carreira de professor, o Nível I corresponde ao Nível Médio na modalidade Normal ocorrendo o acréscimo dos demais Níveis por titulação, como é o caso do Nível VI, correspondente à licenciatura plena e título de Doutor. No caso do especialista de educação, o Nível I corresponde à licenciatura curta e o Nível V à licenciatura plena em pedagogia e título de Doutor (RIO GRANDE DO NORTE, 2006).

Com relação ao ingresso dos professores e especialistas de educação na rede estadual, dependerá de aprovação prévia em concurso público de provas e títulos, assumindo um regime de trabalho parcial de 30 horas, integral de 40 horas ou com dedicação exclusiva à atividade docente.

8 Com o Fundeb, a receita de $20 \%$ dos impostos dos estados e/ou dos municípios devem ir compulsoriamente para o Fundo Estadual. Os recursos voltam na medida do número de matrículas. Assim, abrir mais vagas não significa mais despesas, e sim, mais receita (FERNANDES, 2009).

9 Nível é a posição na estrutura da carreira correspondente à formação e/ou titulação do cargo de professor e especialista da educação. 
A remuneração mensal corresponde, para os professores e especialistas de educação da rede estadual de ensino, ao vencimento básico da Classe da Carreira em que se encontrem, acrescido das vantagens pecuniárias: I - gratificação pelo desempenho do cargo público em regime de dedicação exclusiva, que corresponde a 30\% do vencimento básico; II - adicional por tempo de serviço, equivalendo a $5 \%$ do vencimento básico. O saláriobase é fixado levando-se em consideração uma diferença de $5 \%$ entre as respectivas Classes de Vencimento (RIO GRANDE DO NORTE, 2006).

\section{Remuneração dos Professores da Rede Estadual entre 2005 e 2010 e o PSPN}

As TAB. 2 e 3, a seguir, demonstram os dados quantitativos relacionados ao vencimento do magistério estadual correspondente aos Níveis I e III, Magistério (Normal) e Licenciatura, respectivamente, antes e com o PCCR/RN, de 2006, e com a implementação do PSPN, nos anos de 2009 e 2010, mostrando um acréscimo, nas Classes, de 5\% em média.

\section{TABELA 2}

Trajetória da Remuneração do Professor

Rede Estadual do Rio Grande do Norte - 2005 a 2010 - Nível Médio 30h

\begin{tabular}{|c|c|c|c|c|}
\hline \begin{tabular}{l}
$\infty$ \\
N \\
ज \\
\multirow{1}{U}{}
\end{tabular} & $\begin{array}{c}\text { NÍVEL I - } \\
\text { MAGISTÉRIO } \\
\text { REMUNERAÇÃO } \\
\text { ANTES DO PCCR } \\
\text { (2005) }\end{array}$ & $\begin{array}{c}\text { REMUNERAÇÃO } \\
\text { A PARTIR DO } \\
\text { PCCR (2006) }\end{array}$ & $\begin{array}{c}\text { REMUNERAÇÃO } \\
\text { COM A } \\
\text { IMPLEMENTAÇÃO } \\
\text { DO PSPN } \\
\text { (2009) }\end{array}$ & $\begin{array}{c}\text { REMUNERAÇÃO } \\
\text { COM O } \\
\text { PSPN (2010) }\end{array}$ \\
\hline $\begin{array}{l}\text { A } \\
\text { B } \\
\text { C } \\
\text { D } \\
\text { E } \\
\text { F } \\
\text { G } \\
\text { H } \\
\text { I } \\
\text { J }\end{array}$ & $\begin{array}{l}533,28 \\
536,79 \\
540,48 \\
544,48 \\
548,43 \\
552,70 \\
557,18 \\
561,89 \\
572,78 \\
591,27\end{array}$ & $\begin{array}{l}620,00 \\
651,00 \\
683,55 \\
717,73 \\
763,61 \\
791,29 \\
830,86 \\
872,40 \\
916,02 \\
961,82\end{array}$ & $\begin{array}{c}712,56 \\
748,19 \\
785,60 \\
824,88 \\
866,12 \\
909,43 \\
954,90 \\
1002,64 \\
1052,78 \\
1105,41\end{array}$ & $\begin{array}{c}768,57 \\
807,00 \\
847,35 \\
889,72 \\
934,20 \\
980,91 \\
1029,96 \\
1081,46 \\
1135,53 \\
1192,30\end{array}$ \\
\hline
\end{tabular}

Fonte: Lei Complementar n. 322/06; SINDICATO DOS TRABALHADORES EM EDUCAÇÃO PÚBLICA DO RIO GRANDE DO NORTE (SINTE/RN) 2009/2010; tabelas de implementação do PSPN. 
A Lei Complementar n. 322/06 contemplou 2.587 professores com formação em Nível Médio integrantes da estrutura de carreira do Nível I - Classe A, apresentando um percentual de 16,26\% de acréscimo salarial. Assim, o vencimento de $\mathrm{R} \$ 533,28$ passou para $\mathrm{R} \$ 620,00$ após a implantação do PCCR/RN.

O vencimento do professor em Nível Médio, em final de carreira, corresponde a

$\mathrm{R} \$ 961,82$ e a remuneração do professor com Doutorado em início de carreira, é de R\$1.426,00. Essa diferença salarial nos remete a admitir a importância da formação continuada para a promoção na carreira.

TABELA 3

Trajetória da Remuneração do Professor da Rede Estadual do RN (2005 a 2010) - Licenciatura 30h

\begin{tabular}{|c|c|c|c|c|}
\hline 㱏 & $\begin{array}{c}\text { NÍVEL III - } \\
\text { MAGISTÉRIO } \\
\text { REMUNERAÇÃO } \\
\text { ANTES DO PCCR } \\
\text { (2005) }\end{array}$ & $\begin{array}{c}\text { REMUNERAÇÃO } \\
\text { A PARTIR DO } \\
\text { PCCR (2006) }\end{array}$ & $\begin{array}{c}\text { REMUNERAÇÃO } \\
\text { COM A } \\
\text { IMPLEMENTAÇÃO } \\
\text { DO PSPN } \\
\text { (2009) }\end{array}$ & $\begin{array}{c}\text { REMUNERAÇÃO } \\
\text { COM O } \\
\text { PSPN (2010) }\end{array}$ \\
\hline $\begin{array}{c}\text { A } \\
\text { B } \\
\text { C } \\
\text { D } \\
\text { E } \\
\text { F } \\
\text { G } \\
\text { H } \\
\text { I } \\
\text { J }\end{array}$ & $\begin{array}{l}533,28 \\
536,79 \\
540,48 \\
544,48 \\
548,43 \\
552,70 \\
557,18 \\
561,89 \\
572,78 \\
591,27\end{array}$ & $\begin{array}{l}620,00 \\
651,00 \\
683,55 \\
717,73 \\
763,61 \\
791,29 \\
830,86 \\
872,40 \\
916,02 \\
961,82\end{array}$ & $\begin{array}{c}712,56 \\
748,19 \\
785,60 \\
824,88 \\
866,12 \\
909,43 \\
954,90 \\
1002,64 \\
1052,78 \\
1105,41\end{array}$ & $\begin{array}{c}768,57 \\
807,00 \\
847,35 \\
889,72 \\
934,20 \\
980,91 \\
1029,96 \\
1081,46 \\
1135,53 \\
1192,30\end{array}$ \\
\hline
\end{tabular}

Fonte: Lei Complementar n. 322/06; SINDICATO DOS TRABALHADORES EM EDUCAÇÃO PÚBLICA DO RIO GRANDE DO NORTE (SINTE/RN) 2009/2010; tabelas de implementação do PSPN.

A Lei Complementar n. 322/06 contemplou 2.587 professores com formação em Nível Médio integrantes da estrutura de carreira do Nível I - Classe A, apresentando um percentual de 16,26\% de acréscimo salarial. Assim, o vencimento de $\mathrm{R} \$ 533,28$ passou para $\mathrm{R} \$ 620,00$ após a implantação do PCCR/RN.

O vencimento do professor em Nível Médio, em final de carreira, 
corresponde a $\mathrm{R} \$ 961,82$ e a remuneração do professor com Doutorado em início de carreira, é de $\mathrm{R} \$ 1.426,00$. Essa diferença salarial nos remete a admitir a importância da formação continuada para a promoção na carreira.

TABELA 3

Trajetória da Remuneração do Professor da Rede Estadual do RN (2005 a 2010) - Licenciatura 30h

Fonte: Lei Complementar n. 322/06; SINDICATO DOS TRABALHADORES EM EDUCAÇÃO PÚBLICA DO RIO GRANDE DO NORTE (SINTE/RN) - 2009/2010; tabelas de implementação do PSPN.

\begin{tabular}{|c|c|c|c|c|}
\hline 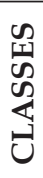 & $\begin{array}{c}\text { NÍVEL III - } \\
\text { MAGISTÉRIO } \\
\text { REMUNERAÇÃO } \\
\text { ANTES DO PCCR } \\
\text { (2005) }\end{array}$ & $\begin{array}{c}\text { REMUNERAÇÃO } \\
\text { A PARTIR DO } \\
\text { PCCR (2006) }\end{array}$ & $\begin{array}{c}\text { REMUNERAÇÃO } \\
\text { COM A } \\
\text { IMPLEMENTAÇÃO } \\
\text { DO PSPN } \\
\text { (2009) }\end{array}$ & $\begin{array}{c}\text { REMUNERAÇÃO } \\
\text { COM O } \\
\text { PSPN (2010) }\end{array}$ \\
\hline A & 663,24 & 868,00 & 997,58 & 1076,00 \\
\hline B & 686,25 & 911,40 & 1047,45 & 1129,80 \\
\hline $\mathrm{C}$ & 710,41 & 956,97 & 1099,84 & 1186,29 \\
\hline $\mathrm{D}$ & 735,79 & $1.004,82$ & 1154,83 & 1245,60 \\
\hline E & 762,42 & $1.055,06$ & 1212,57 & 1307,88 \\
\hline F & 790,40 & $1.107,81$ & 1273,20 & 1373,28 \\
\hline G & 819,77 & $1.163,20$ & 1336,86 & 1441,94 \\
\hline $\mathrm{H}$ & 850,60 & $1.221,36$ & 1403,70 & 1514,04 \\
\hline I & 882,98 & $1.282,43$ & 1473,89 & 1589,74 \\
\hline J & 916,98 & $1.346,55$ & 1547,58 & 1669,23 \\
\hline
\end{tabular}

Levando-se em consideração os 2.106 professores do Nível III - Classe A com Licenciatura, o percentual de acréscimo salarial foi de 30,87\%, passando de $\mathrm{R} \$ 663,24$ para $\mathrm{R} \$ 868,00$.

Do exposto, verifica-se que, na implementação do PCCR/RN, conforme detalhado na TAB. 2, o percentual de aumento da remuneração dos professores Nível I variou entre 16,26 \% para a classe A, e 62,67\% para a classe J, considerando, como parâmetro, os salários aplicados anteriores ao PCCR.

Observa-se, entretanto, um elemento importante para o diferencial entre o início e o final da carreira: a necessidade da efetivação da progressão, seja por tempo de serviço, anterior ao plano, seja pela avaliação de desempenho, pós-plano. Considerando a implementação do PSPN, a variação de aumento percentual da classe inicial (A) foi de 
apenas 14,9\%; e da classe final (J), de 14,88\%.

Analisando a TAB. 3, o aumento da remuneração dos professores Nível III variou 30,87\%, na classe inicial (A), e 46,85\%, na classe final (J), com a implementação do PCCR. Com a implementação do PSPN não houve variação elevada de aumento no percentual das classes A e J: ambas obtiveram um acréscimo de apenas 14,9\%.

A análise evidencia que a implementação do PCCR/RN proporcionou uma razoável melhoria na remuneração dos professores em ambos os níveis apresentados. Observa-se que, com o PSPN, apesar da sua importância enquanto proposição de uma política de valorização docente, houve um pequeno efeito na melhoria da remuneração em termos percentuais, seja em relação ao nível médio ou à licenciatura.

\section{O PCCR municipal de Natal/RN}

O Plano de Cargos, Carreira e Remuneração e o Estatuto do Magistério da rede municipal de ensino de Natal foram aprovados pela Lei Complementar n. 058/04 que revogou a Lei Complementar n. 016, de 02 de julho de 1998, que tratava do antigo Plano. Com a nova legislação, o quadro de carreira do magistério passou a ser constituído por professores estatutários que exercem a docência ou ofertam suporte pedagógico. A estrutura da carreira está pautada em dois Níveis e quinze Classes (NATAL, 2004).

A remuneração do professor corresponde ao vencimento relativo a sua posição no Nível e na Classe da carreira, acrescida das vantagens pecuniárias a que fizer jus sendo: gratificação de titulação em mestrado ou de doutorado. Essa classificação corresponde a 20\% e $40 \%$, respectivamente, do vencimento do professor, incluindo, ainda, a gratificação de dedicação exclusiva, no valor correspondente a $50 \%$ do vencimento do respectivo professor (NATAL, 2004).

Considera-se vencimento básico inicial da carreira do magistério o fixado para o Nível 1 na Classe A; o Nível 2 da carreira corresponde ao coeficiente de 1,20 do fixado para o Nível 1. O valor dos vencimentos referentes às Classes da carreira do magistério é obtido pela aplicação 
do coeficiente de 1,05 sobre o valor do vencimento da Classe anterior do Nível correspondente. A remuneração da carga suplementar deve ser proporcional ao número de horas, adicionadas à jornada de trabalho do professor, calculadas sobre o seu vencimento (NATAL, 2004).

\section{Remuneração dos professores municipais de Natal e o PSPN - 2006 a 2010}

A TAB. 4, a seguir, apresenta a correlação entre as cargas horárias de 20 e de 40 horas semanais dos professores somente com Magistério (cargo em extinção), conforme a Lei Complementar n. 058/04, implementada em 2006 :

\section{TABELA 4}

Salário-base dos professores de Nível NE-1 com a implementação do PCCR e do PSPN no período 2006-2010 - Natal/RN

\begin{tabular}{|c|c|c|c|c|c|c|}
\hline \multirow{4}{*}{ 崩 } & \multicolumn{6}{|c|}{ NÍVEL NE-1* } \\
\hline & \multicolumn{2}{|c|}{2006} & \multirow{3}{*}{$\begin{array}{c}2007 \\
\text { SALÁRIO } \\
\text { BASE 20h } \\
\text { REAJUSTE } \\
23,74 \%\end{array}$} & \multicolumn{2}{|c|}{2009} & \multirow{3}{*}{$\begin{array}{c}2010 \\
\text { SALÁRIO } \\
\text { BASE 20h } \\
\text { REAJUSTE } \\
4,5 \%\end{array}$} \\
\hline & $20 \mathrm{~h}$ & $40 \mathrm{~h}$ & & $20 \mathrm{~h}$ & $40 \mathrm{~h}$ & \\
\hline & $\begin{array}{c}\text { SALÁRIO } \\
\text { BASE }\end{array}$ & $\begin{array}{c}\text { SALÁRIO } \\
\text { BASE }\end{array}$ & & $\begin{array}{c}\text { SALÁRIO } \\
\text { BASE }\end{array}$ & $\begin{array}{l}\text { SALÁRIO } \\
\text { BASE }\end{array}$ & \\
\hline A & 505,44 & $1.010,88$ & 625,43 & 738,52 & $1.477,04$ & 771,75 \\
\hline B & 530,71 & $1.061,42$ & 656,70 & 775,45 & $1.550,89$ & 810,34 \\
\hline $\mathrm{C}$ & 557,25 & $1.114,49$ & 689,54 & 814,22 & $1.628,44$ & 850,86 \\
\hline $\mathrm{D}$ & 585,10 & $1.170,21$ & 724,00 & 854,93 & $1.709,86$ & 893,40 \\
\hline $\mathrm{E}$ & 614,37 & $1.228,73$ & 760,22 & 897,68 & $1.795,35$ & 938,07 \\
\hline $\mathrm{F}$ & 645,09 & $1.290,17$ & 798,23 & 942,56 & $1.885,12$ & 984,97 \\
\hline G & 677,34 & $1.354,68$ & 838,14 & 989,69 & $1.979,37$ & $1.034,22$ \\
\hline $\mathrm{H}$ & 711,20 & $1.422,41$ & 880,03 & $1.039,17$ & $2.078,34$ & $1.085,93$ \\
\hline I & 746,76 & $1.493,52$ & 924,04 & $1.091,13$ & $2.182,26$ & $1.140,23$ \\
\hline $\mathrm{J}$ & 784,11 & $1.568,22$ & 970,25 & $1.145,69$ & $2.291,37$ & $1.197,24$ \\
\hline $\mathrm{L}$ & 823,30 & $1.646,61$ & 1018,75 & $1.202,97$ & $2.405,94$ & $1.257,10$ \\
\hline M & 864,46 & $1.728,92$ & $1.069,68$ & $1.263,12$ & $2.526,24$ & $1.319,96$ \\
\hline $\mathrm{N}$ & 907,67 & $1.815,35$ & $1.123,16$ & $1.326,28$ & $2.652,55$ & $1.385,96$ \\
\hline $\mathrm{O}$ & 953,06 & $1.906,11$ & $1.179,31$ & $1.392,59$ & $2.785,18$ & $1.455,26$ \\
\hline $\mathrm{P}$ & $1.000,13$ & $2.001,40$ & $1.238,27$ & $1.462,22$ & $2.924,44$ & $1.528,02$ \\
\hline
\end{tabular}

Fonte: Lei Complementar n. 058/2004; SINDICATO DOS TRABALHADORES EM EDUCAÇÃO PÚBLICA DO RIO GRANDE DO NORTE (SINTE/RN) 2009/2010.

Nota: *Professores com Magistério - nível Médio. 
Em 2006, o salário-base do professor NE-1, com 20 horas (magistério), letra (A) correspondia a $\mathrm{R} \$ 505,44$ e o da última letra, a letra (P), equivalia a $\mathrm{R} \$ 1.000,13$ ocorrendo, pois, uma diferença de $97,8 \%$. O valor de $\mathrm{R} \$$ $1.010,88$ para NE-1 (magistério) com 40 horas, letra (A), e 2.001,40 para NE-1, letra $(\mathrm{P})$, traz uma diferença semelhante à anterior, ou seja, de 97,9\%.

Em 2007, os professores tiveram um reajuste de $23,74 \%$, passando o salário- base do professor NE-1(A), com 20 horas, para $\mathrm{R} \$ 625,43$. No ano de implementação do PSPN, em 2009, os professores tiveram um reajuste de 18,08\% ficando, o NE-1(A) com um salário-base de $\mathrm{R} \$ 738,52$, com 20h, e R $\$ 1.477,04$, com 40 horas.

Em 2010, os professores tiveram um reajuste de 4,5\%, prazo fixado para o término da implementação do PSPN, e o salário-base do NE-1(A) passou para $\mathrm{R} \$ 771,75$ e o do $\mathrm{NE}-1(\mathrm{P})$ para $\mathrm{R} \$ 1.528,02$. Considera-se que o reajuste dos professores com 40 horas, cujas Classes são descritas na TAB. 4, acima, terão os seus salários-base dobrados tendo, como referência, o valor correspondente ao professor de 20 horas.

Considerando a legislação como parâmetro de reajuste, o MEC, baseado em Parecer da Advocacia Geral da União, fixou o Piso Nacional, em 2010, no valor de $\mathrm{R} \$ 1.024,67$. Isto, de acordo com a atual previsão de reajuste $(15,294 \%)$, elevaria o Piso à quantia de $\mathrm{R} \$ 1.181,34$, para 2011, conforme informações da TAB. 1.

Com referência à implantação do PSPN, em 2010, e conforme o demonstrado nas TAB. 2 e 3, a rede municipal de Natal/RN vem apresentando valores superiores em relação àqueles exigidos legalmente. Exemplo: se considerarmos o reajuste do PSPN, o professor somente com o magistério e com 20 horas receberia $\mathrm{R} \$ 512,33$, e o valor correspondente a $\mathrm{R} \$ 1.024,67$ seria para o professor com 40 horas. E, conforme os dados da TAB. 4, o professor de 20 horas iniciante estaria recebendo $\mathrm{R} \$ 771,75$ e aquele em final de carreira receberia $\mathrm{R} \$ 1.528,02$, apresentando, assim, diferenças de $\mathrm{R} \$ 259,12$ e $\mathrm{R} \$ 503,35$, respectivamente.

A TAB. 5, a seguir, apresenta os dados salariais do período 2006 a 2010 do magistério municipal da rede de ensino de Natal/RN, referente aos professores N1, com Graduação, e N2, com Pós-Graduação. 
TABELA 5

Salário-base dos professores de Nível N1 e N2 com a implementação do PCCR e do PSPN no período 2006-2010 - Natal/RN

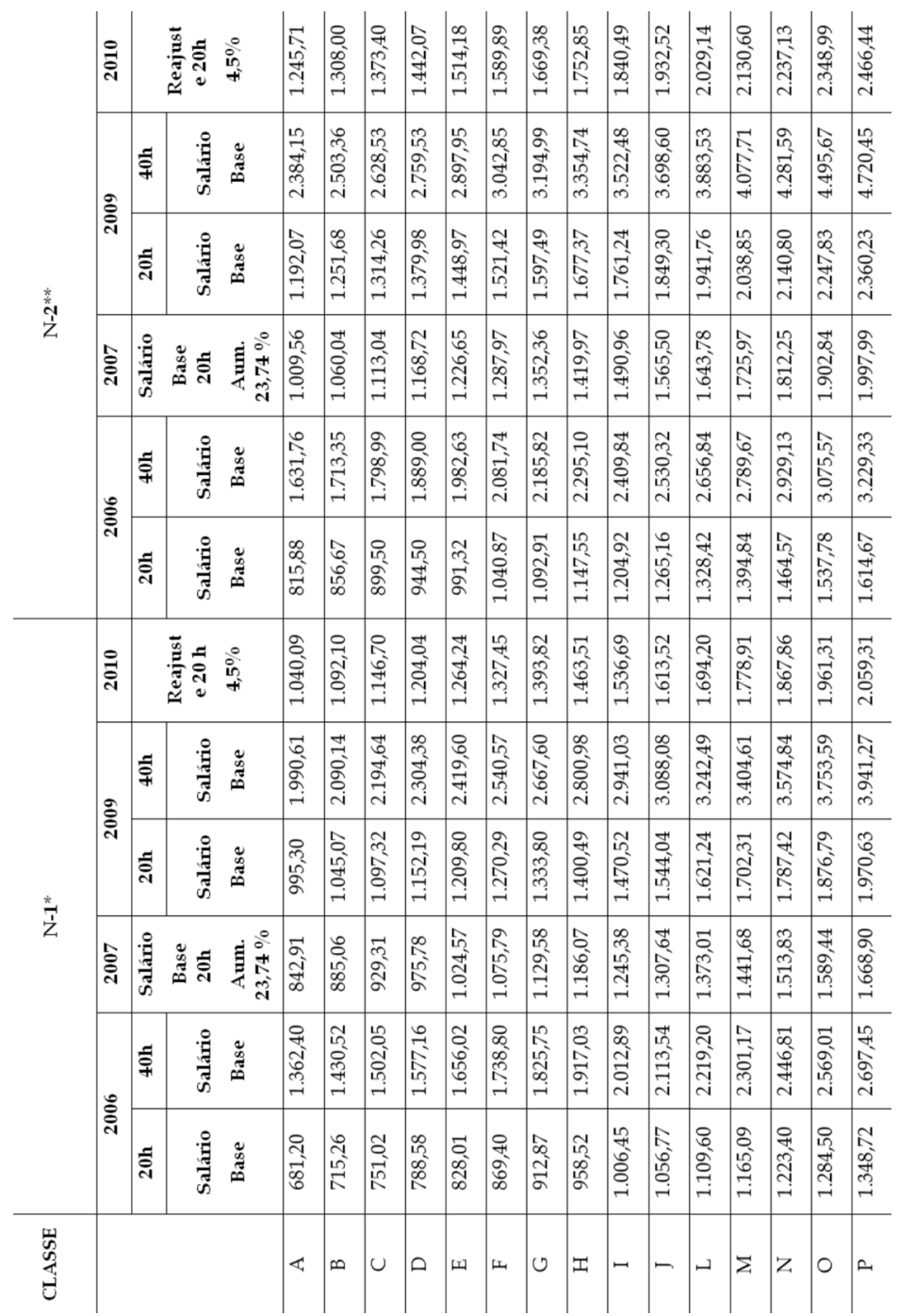

Fonte: Lei Complementar do Legislativo Municipal de Natal/RN, $\mathrm{n}^{\circ}$ 058/2004; Secretaria Municipal de Educação -2007; SINTE/RN, 2010.

Nota: *Professores N-1, com Graduação; **Professores N-2, com Pós-Graduação. 
No ano de 2006, como resultado do enquadramento dos professores ao PCCR municipal, os salários apresentaram diferenças conforme os seus reajustes tomando, por base, nesse momento, somente duas categorias, a saber: o salário-base do N1 (A), 20 horas, correspondendo a R \$681,20 e o do N1 (A), 40 horas, a R\$1. 362,40. Para o N2 (Pós-Graduação), letra (A), com 20 horas, o salário-base correspondia a $\mathrm{R} \$ 815$, 88 e para o N2, letra (A), com 40 horas, $\mathrm{R} \$ 1.631,76$.

No ano de 2007, os professores tiveram um reajuste de $23,74 \%$, elevando o salário do N1(A), 20 horas, para R 842,91 e o do N2 (A), 20horas, para $\mathrm{R} \$ 1.009,56$. Em 2009, o reajuste foi de 18,08\% passando o salário-base do N1(A), 20 horas, para R \$995,30 e o do N2 (A), 20 horas, para R \$1.192,07. Em 2010, o reajuste foi de 4,5\% para todos os níveis e classes.

Considerando o exposto, observa-se que a definição de um Piso Salarial Nacional de R \$ 950,00, em 2008, não impactou a remuneração dos professores da rede municipal de Natal, com graduação e pós-graduação, em virtude dos reajustes e do enquadramento dos professores no PCCR municipal.

Com referência à jornada integral de 40 horas, o único concurso após a implantação do PCCR, promovido pela Prefeitura de Natal, foi para "educador infantil", em 2008, com ingresso em 2009. Ou seja, o pessoal do magistério do quadro municipal possui 40 horas de duas formas: a) por concurso público que incorpore outra matrícula; b) com adesão à carga suplementar.

Com relação aos valores de remuneração, considera-se a incorporação da promoção horizontal e de gratificações, podendo ser, também, quando caracterizado como: instituição com difícil acesso, adicional noturno e Gratificação de Incentivo ao Magistério (GIM).

No que se refere ao enquadramento, 1.217 professores possuíam cursos de graduação, pós-graduação (na maioria especialização) e recebiam como nível médio. Desse montante, 523 tiveram uma correção salarial de $20 \%$; 611 , um reajuste de $54 \%$; e 63 , obtiveram $61 \%$. Os outros tiveram ganhos salariais em virtude da elevação da escolaridade.

No que se refere à promoção na carreira de uma para outra classe imediatamente superior, a Lei Complementar n. 058/04 requer que 
seja feita avaliação de desempenho em face da qualificação profissional (NATAL, 2004). Essa promoção na carreira é disciplinada em regulamento definido pela Comissão de Gestão do Plano de Carreira do Magistério Público Municipal e aprovado por ato do Executivo. Enquanto a avaliação de desempenho está sendo implementada na rede municipal, o mesmo não ocorre na rede estadual.

\section{Promoção no PCCR municipal: a avaliação de desempenho}

A promoção na carreira, item que traz muitas discussões, destaca que a mudança de um professor de uma classe para outra imediatamente superior, dar-se-á por avaliação de desempenho em face da sua qualificação profissional. Essa qualificação poderá ser concedida ao titular de cargo de professor que tenha cumprido o interstício de quatro anos na classe A e de dois em dois anos nas demais classes da carreira, tendo alcançado o número mínimo de pontos estabelecidos no regulamento das promoções (NATAL, 2004). Como já mencionado, essa promoção na carreira é disciplinada em regulamento definido pela Comissão de Gestão do Plano de Carreira do Magistério Público Municipal. A avaliação será efetivada, anualmente: primeiro na escola e, depois, pela referida Comissão.

A pontuação por desempenho e por qualificação ocorrerá a cada dois anos e observará os seguintes aspectos: cumprimento dos deveres, eficiência no exercício do cargo, permanente aperfeiçoamento e atualização. Junto a esses, outros fatores serão considerados na pontuação, tais como: a) rendimento e qualidade do trabalho; b) cooperação; c) assiduidade e pontualidade; d) tempo de serviço na docência; e) contribuições ao campo da educação. Uma inovação do Plano considera, também, a pontuação via: a) publicações de livros e trabalhos, inclusive de pesquisas, na área da educação e da cultura; b) realização e desenvolvimento de projetos de pesquisas, produção de material didático de interesse da educação relacionado à área de atuação ou habilitação do professor, no âmbito da escola ou dos órgãos do sistema municipal de ensino. Valoriza-se, também, a participação como 
membro nos órgãos colegiados e a integração em projetos relevantes na área artística, cultural ou assistencial.

\section{Considerações finais}

A política de valorização docente é decorrente da implantação da política de Fundos públicos de recursos (Fundef e Fundeb) tendo, como conseqüência, o Piso Salarial Nacional e as Diretrizes Nacionais para os Planos de Cargos, Carreira e Remuneração em âmbito dos estados, do Distrito Federal e dos municípios.

Pazello, Fernandes, Anuatti Neto (2002) e França (2005), em seus estudos, demonstraram impacto positivo do Fundef nos salários dos professores de redes municipais, especialmente em municípios pequenos e de regiões mais pobres.

Estudos realizados dos pelo INEP, em 2003, apresentam uma síntese sobre a situação salarial do magistério no contexto dos gastos com a educação, mais especificamente com o Fundef. Segundo esse instituto, os professores brasileiros ganham menos que outros profissionais do setor público, menos que outros colegas de países de renda per capita equivalente. Além disso, a estrutura da carreira não é estimulante e ocorre uma enorme discrepância salarial entre estados e redes de ensino.

Outros estudos, de forma mais específica os que se referem às carreiras docentes, não refletem o uso de critérios para a composição salarial. Não consideram as progressões dos rendimentos que incidem sobre a formação e o desempenho e, principalmente, sobre a complexidade do trabalho docente. Por várias vezes, as escalas salariais são estabelecidas no setor público estadual ou municipal considerando a restrição orçamentária imposta como critério dominante na definição dos níveis salariais.

No caso específico do Rio Grande do Norte, os docentes da rede estadual de ensino sofrem consequências desastrosas quanto ao crescimento de sua remuneração, principalmente aquela relacionada a sua formação em nível de pós-graduação. $\mathrm{O}$ direito às gratificações não lhe são outorgadas de imediato, haja vista que demoram anos para serem contempladas. 
O PCCR/RN apresenta alguns resultados tais como: a garantia da carreira para os profissionais do quadro suplementar do magistério; a promoção vertical dos professores especialistas; e a correção anual do vencimento base conforme previsto no Parágrafo Único do artigo 33 da Lei Complementar n. 322/06 (RIO GRANDE DO NORTE, 2006). No entanto, verifica-se que a remuneração dos professores não é satisfatória porquanto o direito garantido, nessa Lei, não se efetiva na prática. Assim, a valorização dos professores vem apresentando insignificantes melhorias com a implantação da Lei n. 11.738/08 que regulamentou o Piso Salarial Profissional Nacional.

A legalização da profissão docente para a educação municipal de Natal/RN trouxe melhorias nas condições de trabalho, na remuneração e na formação continuada dos professores da educação básica. No entanto, o preceito legal não garante, por si só, a realização de práticas sociais democráticas que proporcionem a valorização do profissional do magistério da educação básica. Com relação à estrutura de elevação da remuneração com base na qualificação e na experiência acumulada (níveis, classes e letras), ocorre na implementação do PCCR municipal a mudança de nível, apenas, com a avaliação de desempenho. O salário proposto pela Lei do Piso não teve impacto na rede municipal de Natal/RN.

A implementação de Planos de Cargos e Salários em ambas as redes, estadual e municipal, carece de avanços no sentido de sanar alguns pontos de estrangulamentos que ocasionam dificuldades na implantação de uma política efetiva de valorização do magistério referente a: a) prazos de evolução na carreira; b) inclusão de todos os profissionais do magistério; c) formação de Comissão de Avaliação; d) extinção de contratos temporários; e, e) remuneração condigna do profissional da educação.

O PSPN incorpora algumas reivindicações oriundas de momentos históricos de luta salarial dos docentes brasileiros. Ao incorporar essas reivindicações, o Piso apresenta manifestações relevantes e avançadas ao estabelecer uma composição da jornada de trabalho que prevê $2 / 3$ do trabalho docente diretamente com o aluno e 1/3 para o planejamento, a formação e a relação com a comunidade. Essa proposta foi incorporada nos ajustes feitos aos PCCR estadual (RN) e municipal (Natal), por força 
dos movimentos políticos do Sindicato.

Há grande variação da remuneração docente nas diversas administrações podendo ocorrer ainda mais desigualdades econômicas e sociais entre as regiões brasileiras. A remuneração docente precisa ser mais bem equacionada para dar sustentação ao PSPN, pois está ocorrendo a proliferação de múltiplos fatores - externos e internos envolvendo vários agentes em busca de seus interesses (CAMARGO; GOUVEIA; GIL; MINHOTO, 2009).

Para a concretude da remuneração condigna tem que haver uma defesa, como projeto de sociedade, da escola e da valorização do docente e do ensino, respaldada por uma luta política entre governantes e sindicatos. 


\section{Referências}

BRASIL. Constituição (1988). Constituição da República Federativa do Brasil, 1988. Brasília: DF, 1988.

. Congresso Nacional. Emenda Constitucional n. 14 de 12 de setembro de 1996a. Modifica os arts. 34, 208, 211 e 212 da Constituição Federal e dá nova redação ao art. 60 do Ato das Disposições constitucionais Transitórias. Disponível em: <http:/ /www.planalto. gov.br/Ccivil_03/Constituicao/Emendas/Emc/emc14.htm>. Acesso em: 10 nov. 2010.

. Congresso Nacional. Lei n. 9.424 de 24 de dezembro de 1996b. Dispõe sobre o Fundo de Manutenção e Desenvolvimento do Ensino Fundamental e de Valorização do Magistério, na forma prevista no art. $60, \S 7^{\circ}$, do Ato das Disposições Constitucionais Transitórias, e dá outras providências. Disponível em: <http://www.planalto.gov.br/ ccivil_03/Leis/L9424.htm>. Acesso em: 12 dez. 2010.

Congresso Nacional. Lei n. 9.394 de 24 de dezembro de 1996c. Lei de Diretrizes e Bases da Educação Nacional. Disponível em: <http://www.planalto.gov.br/ccivil_03/ Leis/L9394.htm>. Acesso em: 12 dez. 2010.

Congresso Nacional. Lei n. 10.172 de 09 de janeiro de 2001. Aprova o Plano Nacional de Educação e dá outras providências. Disponível em: <http://www.planalto.gov.br/ccivil_03/leis/ leis_2001/110172.htm>. Acesso em: 16 abr. 2010.

Congresso Nacional. Emenda Constitucional n. 53 de 19 de dezembro de 2006. Dá nova redação aos arts. $7^{\circ}, 23,30,206,208,211$ e 212 da Constituição Federal e ao art. 60 do Ato das Disposições Constitucionais Transitórias. Disponível em: <http://www.planalto. gov.br/ccivil_03/constituicao/Emendas/Emc/emc53.htm>. Acesso 
em: 10 nov. 2010.

Congresso Nacional. Lei n. 11.494 de 20 de junho de 2007. Regulamenta o Fundo de Manutenção e Desenvolvimento da Educação Básica e de Valorização dos Profissionais da Educação Fundeb. Disponível em: <http://www.planalto.gov.br/ccivil_03/_ Ato2007-2010/2007/Lei/L11494.htm>. Acesso em: 16 abr. 2010.

. Congresso Nacional. Lei $n^{o} 11.738$, de 16 de julho de 2008.

Regulamenta a alínea " $\mathrm{e}$ " do inciso III do caput do art. 60 do Ato das Disposições Constitucionais Transitórias, para instituir o piso salarial profissional nacional para os profissionais do magistério público da educação básica. Brasília: DF, 2008.

. Ministério da Educação. Portaria Ministerial n. 211 de 10 de março de 2009a. <http:/ / portal.mec.gov.br/index.php?option=com_co ntent\&view=article\&id=12407\&Itemid=725>. Acesso em: 16 maio 2010.

Piso dos professores é lei, mas ainda não foi implantado. Jornal do Senado, Brasília, 09 mar. 2009b. Disponível em: <http:/ / www12.senado. gov.br/noticias/jornal/edicoes/2009/03/09/piso-dos-professores-e-leimas-ainda-nao-foi-implantado>. Acesso em: 03 mar.2010.

Ministério da Educação. Conselho Nacional de Educação.

Resolução CNE/CEB $n^{0} 2$ de 28 de maio de 2009c. Fixa as Diretrizes Nacionais para os Planos de Carreira e Remuneração dos Profissionais do Magistério da Educação Básica Pública. <http://portal.mec.gov.br/dmdocuments/resolucao_cne_ ceb002_2009.pdf>. Acesso em: 20 dez. 2010.

Ministério da Educação. Portaria Ministerial n. 538 de 26 de abril de 2010. <http:/ / portal.mec.gov.br/index.php?option=com_cont ent\&view=article\&id=12407\&Itemid=725>. Acesso em: 12 dez. 2010. 
CAMARGO; GOUVEIA; GIL; MINHOTO. Financiamento da educação e remuneração docente: um começo de conversa em tempos de piso salarial. Revista Brasileira de Política e Administração da Educação, Porto Alegre: ANPAE, 2009 - v.25, n. 2, maio/ago.2009. Disponível em: <www.cnte.org.br> Acesso em: 22 de nov. 2010.

FRANÇA, Magna. Gestão e financiamento da educação. O que mudou na escola? Programa Dinheiro Direto na Escola. Fundef. Natal, RN: EDUFRN, 2005.

NATAL. Lei Complementar n. 058 de 13 de setembro de 2004. Dispõe sobre o Plano de Cargos, Carreira e Remuneração e sobre o Estatuto do Magistério Público Municipal de Natal/RN. Natal, 2004.

PAZELLO, Elaine Toldo; FERNANDES, Reynaldo; ANUATTI NETO, Francisco. Avaliação dos Salários dos Professores da Rede Pública de Ensino Fundamental em tempos de FUNDEF. Revista de Economia Aplicada, São Paulo: SP, v. 8, n. 3, p. 413-437, 2002.

RIO GRANDE DO NORTE. Lei Complementar n. 322 de 11 de janeiro de 2006. Dispõe sobre o Estatuto e o Plano de Cargos, Carreira e Remuneração do Magistério Público Estadual, referente à Educação Básica e à Educação Profissional, e dá outras providências. Diário Oficial do Estado, Natal, 12 jan. 2006. 


\title{
Public teaching appreciation policy: positions, careers and wages plans in the education systems of the state of Rio Grande do Norte, the city of Natal and the national professional minimum salary
}

\begin{abstract}
This study analyzes the Positions, Careers and Wages Plans (PCCR) in the education system of the state of Rio Grande do Norte and the city of Natal/ $\mathrm{RN}$, specifically regarding salaries and the impact of the National Professional Minimum Salary 2008 (PSPN). Theoretically, it is backed up by documents and legislations that steer the teaching appreciation policy, related to the remuneration of teachers of the basic education system, such as: Constitutional Amendments 14/96 and 53/2006 related to Fundef and Fundeb; Law of PSPN number 11.738/2008; Law number 322/2006 that regulates PCCR in the state of RN; Law number 58/2004 that regulates PCCR in the city of Natal/RN; and CNE's Resolution number 02/2009 that establishes the guidelines for the positions, careers and wages plans. Besides these studies, other instruments were also created to measure improvements in the remunerations after the Plans, whose values show the periods after and before the implementation of PSPN 2008. Nowadays Fundeb is the main source of resources for the appreciation of the teaching career, because at least $60 \%$ of its revenue is destined to the maintenance of the PCCRs. We acknowledge that much progress has been made in improving the teaching career in the state of RN, with advances after the implementation of the Minimum Salary. However, no improvements in salary have been noticed in the teaching career in the city of Natal/RN, even though the city has been destining an average of $95 \%$ of Fundeb's resources to the remuneration of education professionals.
\end{abstract}

Keywords: Fundeb, Career Plans, National Minimum Salary.

Recebido: 18/01/2012

Aprovado: 23/06/2012 